\title{
A didatização da canção no livro didático de língua portuguesa
}

\section{The presence of the song in the Portuguese language textbook}

\section{La enseñanza de la canción en el libro de texto de lengua portuguesa}

\author{
Jaqueline Moreto Cabral ${ }^{1}$ (id https://orcid.org/0000-0001-7661-1770 \\ Yuri Andrei Batista Santos ${ }^{2}$ (iD https://orcid.org/0000-0002-3805-0586
}

\begin{abstract}
RESUMO: A presente proposta objetiva analisar a maneira com que a canção, uma prática social de linguagem, é didatizada na constituição do livro didático de língua portuguesa. Nossas análises se encaminham por identificar o tratamento da canção a partir da consideração de três categorias de análise, a saber: 1) gênero discursivo; 2) gênero textual e 3) pretexto à gramática. Alicerçamonos nas teorias de Bakhtin e do Círculo, bem como nas postulações de pesquisadores que endossam essa visão epistemológica e mobilizam tais aportes para a compreensão de distintos objetos de estudo, dentre os quais se encontra, também, o ensino de línguas. Nosso corpus é composto por propostas que didatizam a canção na coleção Português-Linguagens (2015). Dentre os resultados obtidos, destacamos a necessidade de pensarmos a produção do material didático em uma preocupação mais condizente com as reais necessidades comunicacionais dos educandos, uma vez que, no tocante ao trato da canção, a dimensão textual e/ou a dimensão discursiva são superficialmente exploradas pelas didatizações analisadas.
\end{abstract}

PALAVRAS-CHAVE: Canção. Livro didático. Ensino de língua portuguesa.

ABSTRACT: This proposal aims to analyze how the song, a social practice of language, is addressed in the Portuguese textbook. Our analyses are aimed at identifying how the song is employed in the textbook by considering three categories of analysis, namely: 1) discourse genre, 2) textual genre, and 3) pretext for grammar. We rely on the theories of Bakhtin and the Circle, as well as on researches that support this epistemological perspective and employ such contributions to the

\footnotetext{
${ }^{1}$ Mestre em Letras: Linguagens e Representações (UESC) e Professora da rede estadual do Espírito Santo. E-mail: jaquelinemoretocabral@gmail.com.

${ }^{2}$ Doutorando em Filologia e Língua Portuguesa (USP) e em Sciences du Langage (Université de Paris). Bolsista FAPESP (número do processo - 2019/02188-3). E-mail: batista.yuriandrei@gmail.com.
} 
understanding of different objects of study, among them, language teaching. Among the results obtained, we highlight the need to consider the production of the didactic material bearing the real communication needs of the students since, regarding how the song is employed, the textual dimension and/or the discourse dimension are superficially explored by the occurrences analyzed.

KEYWORDS: Song. Textbook. Portuguese language teaching.

RESUMEN: La presente propuesta tiene como objetivo analizarla forma en que la canción, una práctica social del lenguaje, es didactizada en la constitución del manual de lengua portuguesa. Nuestros análisis se dirigen a identificar el tratamiento de la canción desde la consideración de tres categorías de análisis, a saber: 1) género discursivo; 2) género textual y 3) pretexto a la gramática. Nos basamos en las teorías de Bajtín y del Círculo, así como en las postulaciones de los investigadores que hacen suya esta visión epistemológica y movilizan dichas aportaciones para la comprensión de diferentes objetoss de estudio, entre los que también se encuentra la enseñanza de lenguas. Nuestro corpus está compuesto por propuestas que didactizan la canción en la colección Português-Linguagens (2015). Entre los resultados obtenidos, destacamos la necesidad de pensar la producción de material didáctico en una preocupación más coherente con las necesidades comunicativas reales de los alumnos, ya que, en cuanto al tratamiento de la canción, la dimensión textual y/o la dimensión discursiva son exploradas superficialmente por la enseñanza didáctica analizada.

PALABRAS CLAVE: Canción. Manual didáctico. Enseñanza de la lengua portuguesa.

\section{Introdução}

Quando falamos em canção, estamos nos referindo a um produto cultural, o qual carrega consigo marcas de sua gente, suas histórias e, claro, retrata vivências únicas. 0 fato de estar presente em várias situações cotidianas é marca incontestável do papel que este gênero alcançou como artefato cultural e expressão de linguagem, sendo representante de seu povo, de uma cultura, de uma nação. Assim, à medida que a sociedade evolui, a essa também são incorporados novos aspectos e configurações de linguagem, o que se observa em seu caráter de ecletismo e diversidade.

A esfera escolar, do mesmo modo que outras esferas/campos de atividade humana, faz parte da vida do cidadão, tendo grande representatividade e relevância à sua formação social. Para Calissi (2005), é nela que parte dos saberes culturais, além dos curriculares, vão sendo construídos, uma vez que atua como mediadora na aquisição desses saberes. Portanto, através da intervenção escolar, é possível colaborar para o desenvolvimento de sujeitos cada vez mais letrados, participantes das inúmeras práticas sociais, interagindo nas várias situações de uso da linguagem para que, dessa forma, dominem os diversos gêneros que se organizam e integram a vida moderna, entre eles, a canção. As propostas pedagógicas devem ser, portanto, pensadas no intuito de não só ir ao encontro, mas de 
acompanhar as mudanças típicas da contemporaneidade e que atravessam, inclusive, os usos das diversas linguagens.

Como se sabe, o livro didático é um dos recursos metodológicos que se destina a contribuir para a prática docente. É, na maioria expressiva dos casos, o principal suporte de que os docentes dispõem para nortear seu fazer em sala, consequentemente, acaba se tornando, segundo Munakata (2002), indispensável e até inquestionável. Os professores, mesmo que de forma inconsciente, ocupam o lugar de reprodutores dos discursos circundantes no LD (livro didático), o qual constrói um consenso cultural e reafirma tradições para a representação não só da sociedade, mas do mundo.

No compasso dessas considerações, faz-se necessário refletir criticamente a maneira com que o livro didático se constitui como instrumento que propicia o ensino e a aproximação dos sujeitos ante as formas distintas de expressão da linguagem. Por isso, discutimos, no presente artigo, sobre como a canção tem sido didatizada nesse material, o qual se constitui de diferentes gêneros intercalados de modo a subsidiar a prática dos professores. Nos inquerimos, a partir dos aportes de Bakhtin e do Círculo, bem como de outros estudiosos que endossam a teoria dialógica em seus trabalhos, acerca de como o livro didático favorece a abordagem significativa e a reflexão crítica dos conteúdos no contexto escolar das aulas de língua portuguesa.

Propomo-nos, no curso desse espaço de discussão, abordar como a canção, materialidade de linguagem escolhida para nossa análise, é tratada em sua forma didatizada no livro didático de língua portuguesa. Nossa segmentação analítica, acompanhada de reflexão teórica compatível, desenvolve-se de modo a perceber quais dimensões de linguagem são exploradas nas didatizações propostas em torno da canção na coleção de livros analisada. Para isso, nosso debate se resume no entorno da seguinte questão: "A canção no livro didático de língua portuguesa: gênero discursivo, gênero textual ou pretexto à gramática?"

\section{Livro didático, gêneros, canção: do que estamos falando?}

O que se entende por canção? Bem, em toda sua história, a humanidade sempre foi acompanhada, viveu e sentiu através da música. É tão forte sua ligação com a sociedade, que, de acordo com Foucault (2006), seria ela, das artes, a mais sensível às transformações tecnológicas, por estar sempre em constante mudança e adequação, incorporando a si 
novos ritmos e inúmeras possibilidades para sua produção junto ao dinamismo humano. Também a seu respeito, Costa (2003, p. 18) aponta que:

[...] basta saber que se trata de um gênero híbrido, de caráter intersemiótico, pois é o resultado da conjugação entre a materialidade verbal e a materialidade musical (rítmica e melódica); e que essas dimensões são inseparáveis, sob pena transformá-lo em outro gênero.

Esse gênero, portanto, em meio a alguns outros, se faz presente nos materiais didáticos para o ensino de língua. Além de fazer parte da diversidade de gêneros a serem trabalhados em sala, dos quais se fala em documentos oficiais, como os PCN e a Base Nacional Curricular Comum, também propicia a interação, estimula e colabora para um ensino significativo e um posicionamento crítico dos discentes, tanto no âmbito educacional quanto fora dele.

Segundo Gada (2005), reflexões como as de Costa (2003) foram fundamentais para se pensar a canção como resultante de duas linguagens: a verbal e a musical, duas interfaces inseparáveis, de modo que desconsiderá-las é o mesmo que "falar de um corpo esquecendo-se da alma e vice-versa" (FERREIRA, 2002, p. 39). Gada (2005) também reitera que:

[...] lamentavelmente, as canções, em sua maioria, não são amplamente utilizadas, nem enquanto o gênero textual a que pertencem e nem através de todos os recursos que elas possuem em sua essência, ou seja, as possibilidades verbais e não-verbais que elas oferecem [...] (GADA, 2005, p. 116-117).

A dupla materialidade que compõe o gênero pode propiciar, conforme a autora, diferentes formas de leitura e sua inserção nos livros didáticos é justificável também dada sua relevância de caráter social no dia a dia das pessoas, dos alunos que com sua letra e música se identificam e onde se estabelecem ângulos dialógicos, porque assim é "a relação do autor com a vida, ou seja, o estilo artístico não trabalha com palavras, mas com os componentes do mundo, com os valores do mundo e da vida" (BRAIT, 2008, p. 87). Dessa mesma maneira que o estudante se enxerga na canção, de igual modo acontece com o professor, que vê seu comportamento e discursos no material didático adotado, o que nos conduz para uma relação de dialogismo entre ambos. Sobre isso, Brait (2008, p. 96) argumenta que:

[...] não pode separar-se da ideia de que se olha um enunciado, um gênero, um texto, um discurso, como participante, ao mesmo tempo, de uma história, de uma cultura e, também, da autenticidade de um acontecimento, de um evento. [...] Essa perspectiva, justamente pelo seu alcance 
discursivo, pode ser trabalhada em textos produzidos nas mais variadas esferas, nas diferentes atividades englobadas por essas esferas, como condição para compreender tanto a atividade em suas invariáveis quanto os sujeitos que nela atuam e que, apesar de todas as coerções, interferem, atuam estilisticamente na movimentação dessa esfera, de suas atividades, de seus gêneros.

A reunião desses pressupostos é fundamental, para a autora, e é o que implica para que os discursos e também os sujeitos desses discursos sejam atuantes em atividades e movimentos históricos, sociais e culturais. Também é uma forma de se recuperar contextos mais amplos a fim de se compreender melhor a discursividade que constitui os textos, nesse caso, a canção. Em se tratando do uso da linguagem, sabe-se que ela se realiza e é produzida nas diferentes práticas sociais e varia conforme determinado contexto, pois a situação concreta de sua produção Ihe é parte integralmente constitutiva. Por isso, 0 homem pode representar e significar o mundo, porque, além de social, a linguagem, em sua situacionalidade, é histórica e cultural.

Por esse encaminhar, entendemos que os discursos produzidos não surgem do vazio, "porque não falamos no vazio, não produzimos enunciados fora das múltiplas e variadas esferas do agir humano" (FARACO, 2009, p. 126). Ao contrário, todo dizer emerge de condições, situações, finalidades e de escolhas do gênero. E mais:

[...] Falamos apenas através de determinados gêneros do discurso, isto é, todos os nossos enunciados possuem formas relativamente estáveis e típicas de construção do todo. Dispomos de um rico repertório de gêneros de discurso orais (e escritos). Em termos práticos, nós os empregamos de forma segura e habilidosa [...] (BAKHTIN, 2003, p. 282, grifo do autor).

Quando menciona o gênero como formas relativamente estáveis, Bakhtin (2016) nos atenta para uma característica bastante peculiar, pois:

[...] Quando se fala em gênero do discurso, do ponto de vista do Círculo, fala-se de algo que é ao mesmo tempo estável e mutável. O gênero é estável porque conserva traços que o identificam como tal e é mutável porque está em constante transformação, se altera a cada vez que é empregado (SOBRAL, 2009, p. 115).

O fato de ser instável, no caso, mutável, pressupõe que, dependendo das situações, o gênero pode transformar-se em outro, pois as "formas de interação discursiva estão estreitamente ligadas às condições de dada situação social concreta, e reagem com extrema sensibilidade a todas as oscilações do meio social" (VOLÓCHINOV, 2017, p. 107-108), logo, na comunicação discursiva, o gênero pode se reinventar, se ressignificar de acordo com o tempo e espaço, pois "cada época e cada grupo social possui seu próprio repertório" 
(VOLÓCHINOV, 2017, p. 109). Isso explica por que, para Volóchinov (2017), a palavra é um signo ideológico, pois nela se instauram as mudanças que ocorrem na sociedade, haja vista que ela é "capaz de fixar todas as fases transitórias das mudanças sociais, por mais delicadas e passageiras que elas sejam" (VOLÓCHINOV, 2017, p. 106). Os gêneros, portanto, estão em "contínuas transformações, são maleáveis e plásticos", justamente para acompanhar as atividades humanas, as quais são "dinâmicas, e estão em contínua mutação" (FARACO, 2009, p. 127).

Tais afirmações nos permitem defender o livro didático como um gênero do discurso e, ainda, segundo Viana (2011), um gênero formado pela intercalação de outros gêneros, porque nele encontramos diferentes modalidades de enunciados que se organizam composicionalmente por um projeto de dizer didatizante. É um recurso metodológico dialógico e interativo, pois, no sentido bakhtiniano do termo, o professor é alguém que o reinterpreta e o compreende e, frente a esse, posiciona-se, já que:

[...] Toda compreensão de um texto, tenha ele a dimensão que tiver, implica, segundo Bakhtin, uma responsividadee, por conseguinte, um juízo de valor. O ouvinte ou o leitor, ao receber e compreender a significação linguística de um texto, adota, ao mesmo tempo, em relação a ele, uma atitude responsiva ativa: concorda ou discorda, total ou parcialmente; completa; adapta; etc. Toda compreensão é carregada de resposta. [...] Compreender é participar de um diálogo com o texto [...] (FIORIN, 2017, p. 8, grifo do autor).

A finalidade, os processos de produção, de circulação, de recepção são essenciais para que a língua adquira uma materialidade concreta. Assim, o LD não é somente um suporte aos textos, mas é legitimado como gênero do discurso, um objeto histórico-cultural e, de acordo Viana (2011), tramado pela intercalação de outros gêneros. A fim de fortalecer essa concepção, podemos nos ancorar em Bunzen Júnior (2005, p. 28), que aponta:

[...] quando os autores de livros didáticos de Língua Portuguesa, juntamente com outros agentes envolvidos no processo de produção, selecionam/negociam determinados objetos de ensino e elaboram unidades didáticas para ensinar tais objetos, eles estão, no nosso entender, produzindo um enunciado em um gênero do discurso, no sentido bakhtiniano do termo, cuja função social é re(a)presentar para cada geração de professores e estudantes o que é oficialmente reconhecido, autorizado como forma de conhecimento sobre a língua(gem) e sobre as formas de ensino-aprendizagem.

Baseados nos estudos bakhtinianos, podemos dizer que o livro é elaborado seguindo critérios e, portanto, é uma resposta aos documentos oficiais que o regem. Nesse contexto, o livro é: 
[...] um elo na cadeia da comunicação discursiva; como a réplica do diálogo, está vinculada a outras obras - enunciados: com aquela às quais ela responde, e com aquelas que lhe respondem; ao mesmo tempo, à semelhança da réplica do diálogo, ela separada daquelas pelos limites absolutos da alternância entre os sujeitos do discurso (BAKHTIN, 2003, p. 279).

Mais uma confirmação de sua tessitura dialógica, pois "todos os fenômenos presentes na comunicação real podem ser analisados à luz das relações dialógicas que os constituem" (FIORIN, 2017, p. 31). Através dessa responsividade que se pode afirmar que o discurso não é individual, uma vez que se constrói na relação, entre pelo menos dois interlocutores, os quais são seres sociais; ou ainda, na relação entre discursos, nesse caso, no diálogo entre discursos. O diálogo é o princípio constitutivo da linguagem, conforme Barros (2005). Isso leva-nos a acreditar que os sentidos são produzidos apenas quando há o intercâmbio verbal, em que toda voz humana se relaciona com outras e, por isso, o significado de dialogismo vê-se vinculado ao de interação.

O livro didático é, assim, um ato de interação discursiva, na concepção bakhtiniana, moldado e concebido no (in)tenso diálogo entre diferentes discursos que incidem sobre a composição de sua materialidade. A maneira com que este intercala discursos e outros gêneros em sua constituição como gênero secundário (BAKHTIN, 2016) é reiterativa das posições avaliativas de seus produtores e de seus subsequentes projetos de dizer. A didatização que permeia toda a discursividade entretecida na constituição do gênero livro didático e na forma com que este organicamente intercala outros gêneros se apresenta como estratégia que indicia os propósitos educacionais com que o projeto de dizer empreendido visa alcançar seu destinatário: os discentes e os docentes.

Dessa maneira, como destaca Rojo (2012), a preocupação no horizonte escolar contemporâneo é que o ensino seja pautado em uma relação transitiva entre os conteúdos escolares e os contextos reais de sua aplicação, situações concretas de uso que compreendem as realidades sócio-histórico-culturais em que se situam os educandos. Para esse fim, como incluímos a partir das discussões dessa teórica e pelos entrecruzamentos no âmbito acadêmico, vemos uma confluência entre os estudos de letramento e o estudo acerca das modalizações textuais e discursivas pelas quais se materializam os usos de linguagem, os gêneros textuais e os gêneros discursivos.

Essa tendência é contumaz de uma busca por um ensino e, nesse caso específico, pela produção de material didático que se oriente por uma percepção de linguagem 
dimensionada tanto linguisticamente como extralinguisticamente, comprometida com uma educação que responde às reais necessidades dos educandos em face dos contextos em que estes estão inseridos. Dessa maneira, a expectativa é que o projeto de dizer didatizante de um material didático se ocupe mais de suplementar uma formação crítica e significativa frente ao sujeito estudante, do que insistir na reprodução conteudística ou no puro tradicionalismo perceptível na longa tradição do ensimesmado ensino gramatiqueiro, caso do ensino de línguas.

Com a finalidade de pensar a maneira com que o livro didático reflete essas vertentes do ensino de língua portuguesa, analisaremos a maneira com que as didatizações em torno da canção dimensionam a relação do aluno com o uso da linguagem. Destacaremos, então, a seguir algumas distinções teóricas entre as concepções de gêneros textuais e gêneros discursivos, noções necessárias ao nosso gesto analítico.

\section{Gêneros textuais ou gêneros discursivos?}

O enunciado e seus tipos, os gêneros do discurso, de acordo com Bakhtin (2016), são constituídos por elementos indissociáveis, a saber: o conteúdo temático, o estilo e a construção composicional, os quais estão ligados às particularidades que permeiam cada campo de atividade humana. Para o autor, a construção composicional é o elemento que condiz à organização do texto, ou seja, é a estruturação do enunciado e o que mais possibilita identificar o campo e o propósito enunciativo. O estilo, associado com a forma de composição, permite ecoar o tema no texto e associa-se a como se quer dizer, às escolhas de linguagem, à vontade enunciativa. Em termos bakhtinianos, esse componente estilístico reflete a individualidade do enunciado utilizado pelo falante e é flexível conforme o gênero ou esfera.

Essas escolhas dizem respeito à estrutura frasal (sintaxe), ao léxico (vocabulário), ao registro linguístico (formal/informal, gírias) e às preferências gramaticais, no caso de uma linguagem verbal. Logo, nenhuma escolha é ingênua. Dos elementos constituintes do gênero, o estilo e a construção composicional servem ao locutor/autor como marcas linguísticas para declarar suas apreciações valorativas. Por fim, o conteúdo temático referese não somente ao assunto, mas à questão de ordem temática que dá corpo ao enunciado e aos sentidos que emanam do texto. $O$ tema é dado pelo locutor com base em seu juízo de valor sobre determinado conteúdo, sua posição avaliativa e direcionamentos ideológicos. 
Esse elemento, para Rojo e Barbosa (2015), é o mais importante, uma vez que todo texto é elaborado em torno de um tema, conforme axiologias que o viabilizaram.

Vale salientar que existem confusões teóricas em relação aos termos gêneros discursivos e gêneros textuais, sendo essas motivo para muitas discussões na esfera acadêmica. Acontece que há materiais didáticos e até documentos oficiais que parecem não fazer distinção entre as duas concepções, ambas grandemente difundidas no trabalho com o ensino de línguas nos dias atuais.

Antônio Marchuschi (2007), ao partir de um percurso orientado pelo trabalho com o texto, fundamenta sua teoria dos gêneros textuais com base nos postulados bakhtinianos em relação aos gêneros do discurso e aos enunciados concretos, trazendo ao plano do estudo com o texto uma percepção de contextualização e situacionalidade do dizer que até aquele ponto não era tão destacada no plano da linguística textual. Aqui, claramente, o uso da percepção de linguagem nas teorias de Bakhtin e do Círculo e da conceituação em torno dos gêneros reposiciona a compreensão e o estudo da interação verbal na interface dos gêneros textuais e não dos discursivos, como Mikhail Bakhtin pontua, negligenciando as evidentes especificidades que o termo discurso, na acepção bakhtiniana, encerra. Essa apropriação acaba promovendo um equívoco entre as noções de texto e discurso, levando a uma errônea ideia de que se trata de conceitos intercambiáveis e que designam as mesmas coisas. Silva (2012), nesse caminho, aborda as diferenças entre essas linhas de percepção no tocante ao conceito de gêneros e, quanto às trajetórias dos termos de texto e enunciado concreto nas respectivas perspectivas teóricas, a pesquisadora afirma:

[...] Hoje o conceito de texto da linguística textual se aproxima do conceito de enunciado concreto, mas não éo conceito de enunciado concreto. Cada uma dessas noções teóricas tem uma "história de vida" distinta, que parte de um ponto ímpar. Historicamente, a linguística textual parte da materialidade para, depois de décadas, levar em conta as condições concretas de realização dos textos. A teoria bakhtiniana, já na década de 1920, postulava uma jornada em direção oposta e, partindo das condições concretas para a materialidade, nem por um segundo é capaz de considerar a materialidade sem as condições concretas (SILVA, 2012, p. 221-222, grifo nosso).

A diferença expressa entre essas noções, como apresenta a descrição de Silva (2012), observa a forma com que os conceitos de texto e de enunciado concreto, não só apresentam trajetórias de usos distintas como convergem para acepções de linguagem distintas. Fica mais facilmente perceptível quando tencionamos o papel do contexto externo para ambas as noções. Enquanto para a noção de texto, ainda em percepções recentes, 
parte-se da materialidade para separadamente pensar as condições em que estas tomam forma, para a noção bakhtiniana de discurso, as condições extralinguísticas, como segmenta Volóchinov (2017), são constitutivas do dizer e, portanto, são contiguamente analisadas junto às materialidades.

Ao passo que esse contraste endossa diretamente a percepção de discurso apresentada por Bakhtin (2015) quando define o objeto de estudo da metalinguística, vemos que a distância entre ambos os termos se acampa em outra possível coordenada no terreno da teoria dialógica, como apontado em Brait (2012). O enunciado concreto é perceptível como elo na cadeia discursiva, unidades que integram os gêneros do discurso a partir de sua relação de relativa estabilidade, dessa forma, vinculando-se à unidade de tipificação de um gênero, retomando características que demarcam as singularidades daquele tipo de construção.

O texto, por sua vez, como sugere Brait, não pode ser percebido de forma autônoma; ele está diretamente relacionado "ao enunciado concreto que o abriga, a discursos que 0 constituem" (BRAIT, 2012, p. 10). Um texto, então, pode ser constituído por diferentes discursos e, dada sua constituição singular, se relaciona com um determinado tipo de enunciado concreto. Nesse entendimento, ainda que se admita uma relação de proximidade entre os termos texto e discurso, a diferença é inferida na abrangência dos dois termos, uma vez que a dimensão textual está inserida no contexto de tipicidade de dado enunciado concreto e suas feições discursivas, considerando-se aqui os aspectos linguísticos e extralinguísticos que integram a linguagem.

Ambas as conceituações figuram como unidades de percepção da linguagem, diferenciadas na trajetória de seu uso e, no âmbito da teoria dialógica, o gênero textual tem uma abrangência um tanto menor que os gêneros discursivos, os quais se ocupam da percepção do sentido e do uso da linguagem em um escopo mais amplo e complexo. Quando observamos as duas diferenças que traçamos em relação aos conceitos, observamos que a noção de gênero textual é tendenciada a limitar-se a uma realização de teor linguístico, em que o contexto externo não é concomitantemente percebido na concretude da linguagem, mas observado de forma separada e, em alguns casos, até mesmo acessória.

Ressaltamos que a distinção proposta aqui considera a importância dos percursos teóricos imbricados nos usos de cada conceito e, ainda que reflitamos as diferenças, não 
podemos deixar de levar em consideração como os diálogos entre ambas as noções podem ser benéficos na produção e circulação de conhecimento sobre a linguagem e, especificamente, seu ensino. Por outro lado, a confusão teórica quanto ao emprego da construção "gênero discursivo ou textual", que sugere uma sinonímia entre os termos, deve ser coerentemente discutida, uma vez que o uso adequado das terminologias favorece uma melhor compreensão das finalidades e percepções que seus respectivos usos corroboram. Observaremos como as especificidades do tratamento terminológico incide sobre a produção do material didático de língua portuguesa e, consequentemente, como o material didático dimensiona o ensino do gênero canção.

\section{Análise das canções e suas didatizações}

Objetivamos empreender um gesto de análise, nessa seção, tendo por base as canções didatizadas na coleção Português-Linguagens (CEREJA; MAGALHÃES, 2015), de modo a observar as concepções de língua (gem) que sustentam as propostas a partir desse gênero. Nosso intuito foi observar sob qual perspectiva a canção é contemplada, apontando quais níveis de percepção são considerados na tessitura da linguagem dessas canções. Definimos para isso as distinções: 1. Gênero discursivo; 2. Gênero textual e 3. Pretexto para ensino gramatical.

Além das já mencionadas categorias de gêneros discursivos e gêneros textuais e suas respectivas particularidades, destacamos, ainda, uma terceira distinção que se voltou ao uso da canção como um pretexto para o ensino da gramática. Como já foi mencionado por Gada (2005), as materialidades da linguagem didatizadas em materiais didáticos acabam por servir de suporte à transmissão conteudística. Aqui estamos diante de uma forma de ensino tradicionalista, em que o conhecimento sobre a estrutura gramatical é superior ao da linguagem em seu funcionamento discursivo. Devido a essa valorização da estrutura linguística, a língua adquire um fim em si mesma, ou melhor, se objetiva a conhecer 0 sistema que a compõe e não o seu uso e aplicação em contextos concretos e reais.

O Manual do professor é destinado às reflexões teórico-metodológicas por parte dos autores. A respeito da Português - Linguagens e sua concepção de língua(gem), os autores dizem que:

[...] A língua, nessa obra, não é tomada como um sistema fechado e imutável de unidades e leis combinatórias, mas como um processo dinâmico de interação, isto é, como um meio de realizar ações, de agir e de atuar 
sobre o outro. Assim, o trabalho linguístico não pode se limitar à frase (o que não significa que, às vezes, não se deva trabalhar com frase). Deve também ser considerado o domínio do texto e, mais que isso, o do discurso, ou seja, o texto inserido numa situação concreta e única [...] (CEREJA; MAGALHÃES, 2015, p. 302, grifo nosso).

Diante do exposto, ficou claro que os elaboradores reconhecem que as dimensões textuais e discursivas são importantes para o aprendizado da língua em detrimento a níveis puramente sistêmicos. A inserção do texto "numa situação concreta e única", demonstrou diálogo com as propostas do arcabouço bakhtiniano em relação às situações concretas de uso da linguagem e ao que Street (2014) propôs sobre a relevância do uso da linguagem em vínculo com as características da situação comunicativa.

Os autores citaram Mikhail Bakhtin e estudiosos da linguística textual, como Bronckart, Dolz e Schnewly. Nomeadamente, a coleção ressaltou no seguinte trecho:

[...] Segundo Bakhtin, todos os textos que produzimos, orais ou escritos, apresentam um conjunto de características relativamente estáveis, tenhamos ou não consciência delas. Essas características configuram diferentes textos ou gêneros textuais ou discursivos, que podem ser caracterizados por três aspectos básicos coexistentes: o tema, o modo composicional (a estrutura) e o estilo (usos específicos da língua) (CEREJA; MAGALHÃES, 2015, p. 279, grifos nosso).

Ao mencionarem o nome de Bakhtin, pareceu-nos que manteriam diálogo com seus postulados. Porém, de partida, chamamos atenção para alguns equívocos em relação às concepções teóricas, pois notamos o uso do termo "textos" na primeira linha da citação, onde o mesmo parece fazer ligação entre a unidade textual e o conceito de enunciado concreto para Bakhtin. Entretanto, ao fazerem essa correlação, os elaboradores afirmam à frente que a relativa estabilidade a qual apresentam os textos configura "gêneros textuais ou discursivos", usando da alternância como se ela indicasse uma correlação por sinonímia entre os termos.

Ao longo da coleção analisada, identificamos nos seus quatro volumes (60 ao $9^{\circ}$ ano), o total de nove canções. Em linhas gerais, notamos que nenhuma proposta de atividade desenvolve no aluno um olhar que explora a dupla constituição semiótica que integra a materialidade do gênero canção, as linguagens verbal e musical. Essa observação, por um lado, demonstra que as didatizações em análise negligenciam a singularidade da expressão de linguagem que integra a canção e, por outro lado, aponta, em princípio, uma preferência dos autores para com o trabalho da dimensão verbal que compõe as canções, o que pode provocar no educando a interpretação de que os sentidos se concretizariam apenas na 
dimensão verbal.

Nas questões 1 e 2 didatizadas sobre a canção "Vermelho", identificam-se aspectos pertinentes a uma abordagem puramente gramatiqueira de ensino da língua. Tratando-se de uma perspectiva que afirma se orientar pela percepção do discurso e da textualidade, como apresentado pelos autores na concepção de linguagem da coleção, é incoerente observar que, em ponto algum das didatizações, vemos menção a quaisquer aspectos relacionados à contextualização da canção, seja considerando-o como constitutivo ou paralelo ao dizer. Os conhecimentos linguísticos são um fim em si mesmo, quando se voltaram unicamente para transmissão dos conteúdos Sujeito e Predicado, em detrimento do destaque, por exemplo, a qualquer finalidade que ambientasse a materialidade em questão e suas possíveis relações com seus contextos de produção ou de circulação. 0 aprendizado da língua, em exemplos como as didatizações para a canção "Vermelho", se sugere como uma atividade que negligenciaria o elo de significância e transitividade frente aos contextos de uso da linguagem.

Figura 1- Didatizações em torno da canção "Vermelho", 70 ano

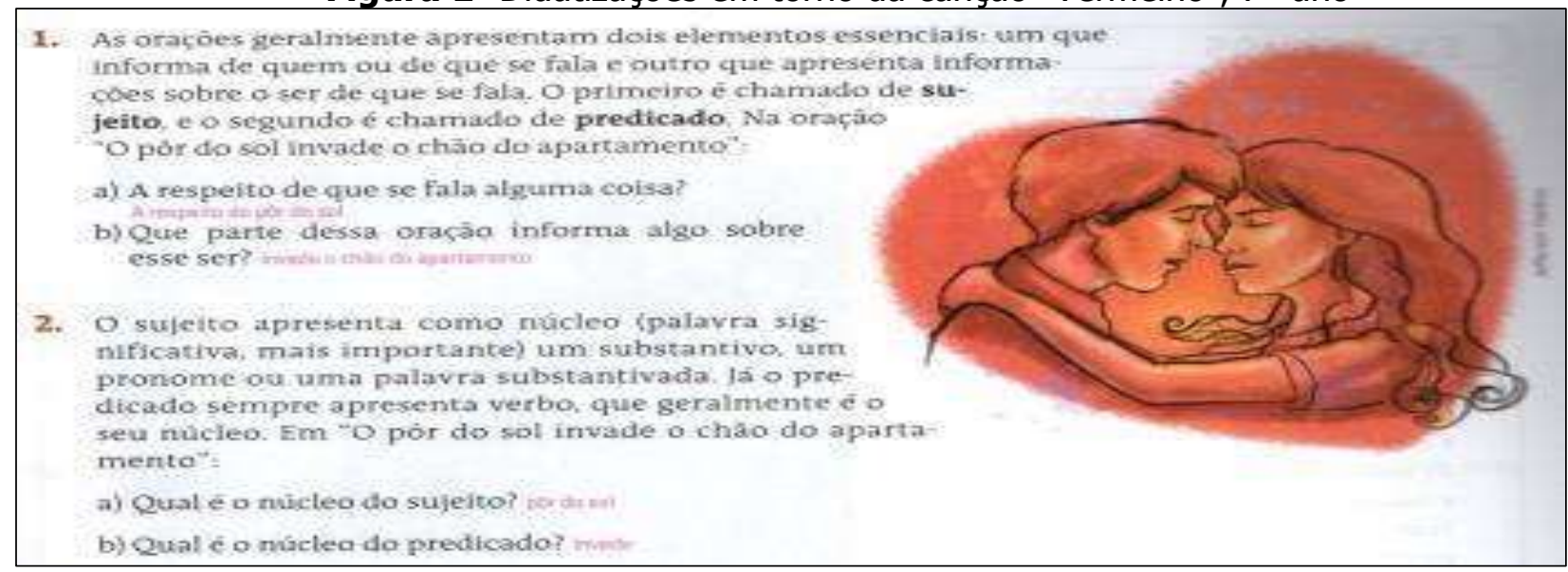

Fonte: Cereja e Magalhães (2015, p. 89)

Nas atividades propostas acerca de "Do it", verificamos que houve preponderância para o trabalho com classe a gramatical Verbo e de sua função na estrutura frasal da canção, com certa abertura para se pensar em aspectos textuais ou discursivos. Em sua maioria, as questões segmentam o ensino gramatical, porém, na questão 2, a reflexão gramatical é acompanhada de uma sugestão para as possíveis projeções entre locutor e interlocutores na textualidade da canção, quando é proposto ao aluno cogitar a relação entre o eu-lírico e os usos do imperativo na canção. Na questão 4, por sua vez, propõe-se uma correlação entre as características singulares da canção e do poema quanto à 
sonoridade. Nessa aproximação, é evocado no aluno seu conhecimento prévio acerca das particularidades na construção composicional de ambos os gêneros, ao que observamos uma inter-relação entre o nível textual com a dimensão discursiva, entrevista na alusão às características dos enunciados concretos em diálogo.

Se tomarmos a visão de gênero textual mais restritiva aos aspectos de sua realização linguística, como destacado anteriormente, veremos que nas propostas de didatização em torno da canção "Do it", existe certa vazão para pensar a estruturação das partes que the compõem, como a versificação, as rimas, o lirismo na identificação do eu-lírico etc. A questão é que esses aspectos da textualidade, relacionados à condição linguística apenas, sinalizam uma abordagem superficial dos aspectos textuais e discursivos, uma vez que a centralidade das didatizações é o trabalho com a classe gramatical verbo.

Figura 2 - Didatizações em torno da canção "Do it"

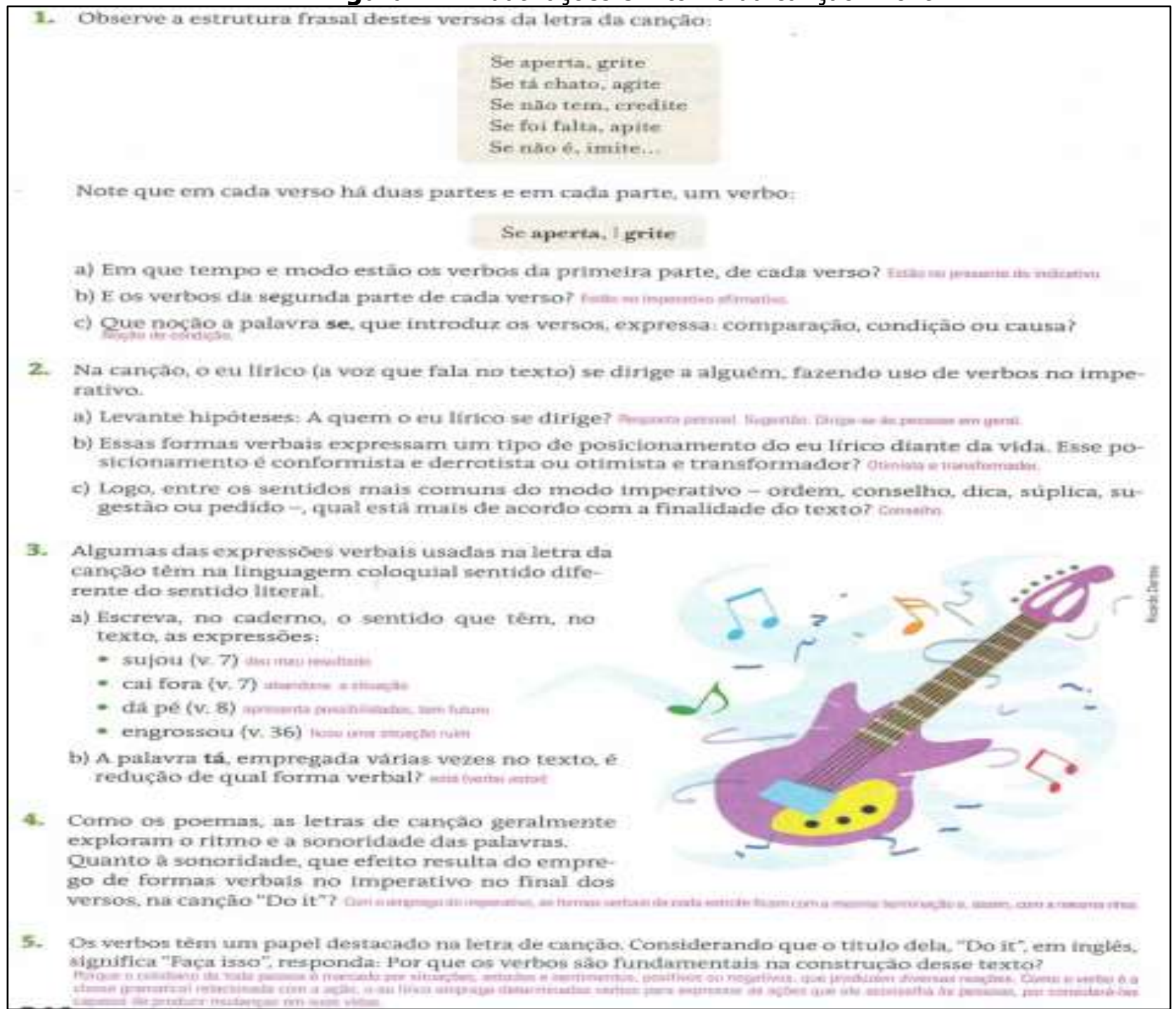

Fonte: Cereja e Magalhães (2015, p. 245) 
Em "A formiga", as questões estimulam o estudante a reconhecer a classificação da categoria gramatical Substantivo no decorrer de todas as atividades propostas. Contudo, na alternativa (a) da questão 1 , percebemos um breve encaminhamento para 0 funcionamento do sentido, quando é sugerido que analisem os significados que as palavras teriam na visão de uma personificação da formiga e na visão de mundo do ser humano. Existe nesse ponto certo espaço para pensar os discursos entretecidos na produção de sentidos na materialidade verbal da canção. Já a partir da letra (b), entretanto, as questões novamente delineiam uma atenção central para com a estrutura gramatical, discutindo o uso do substantivo na segmentação linguística. O propósito da atividade com a canção é, assim, eminentemente a discussão do uso do substantivo na segmentação linguística, uma vez que, em todas as propostas de atividade, sua condição enquanto termo gramatical é claramente enfatizada.

Figura 3 - Didatizações em torno da canção "A formiga", $6^{\circ}$ ano

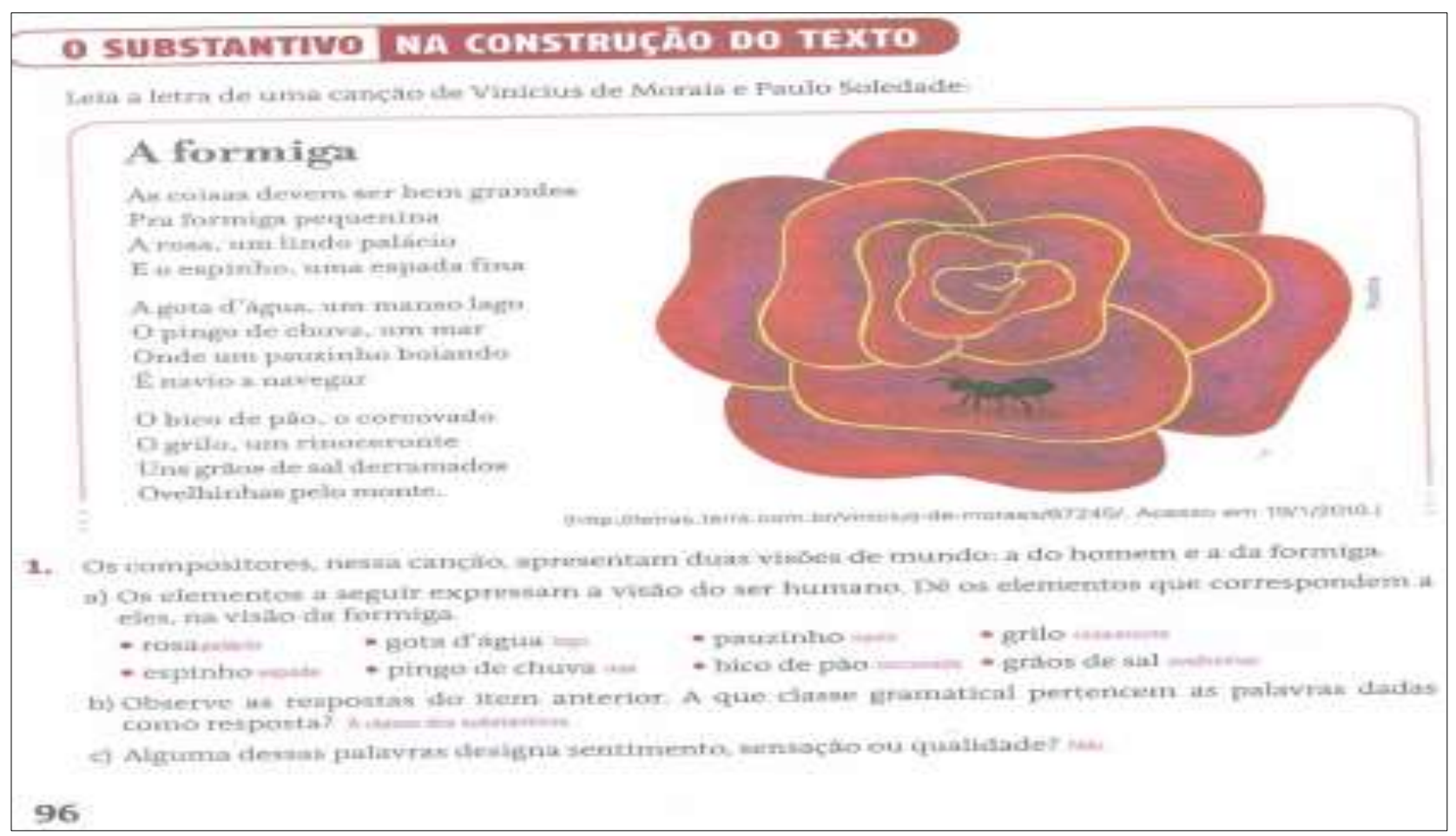




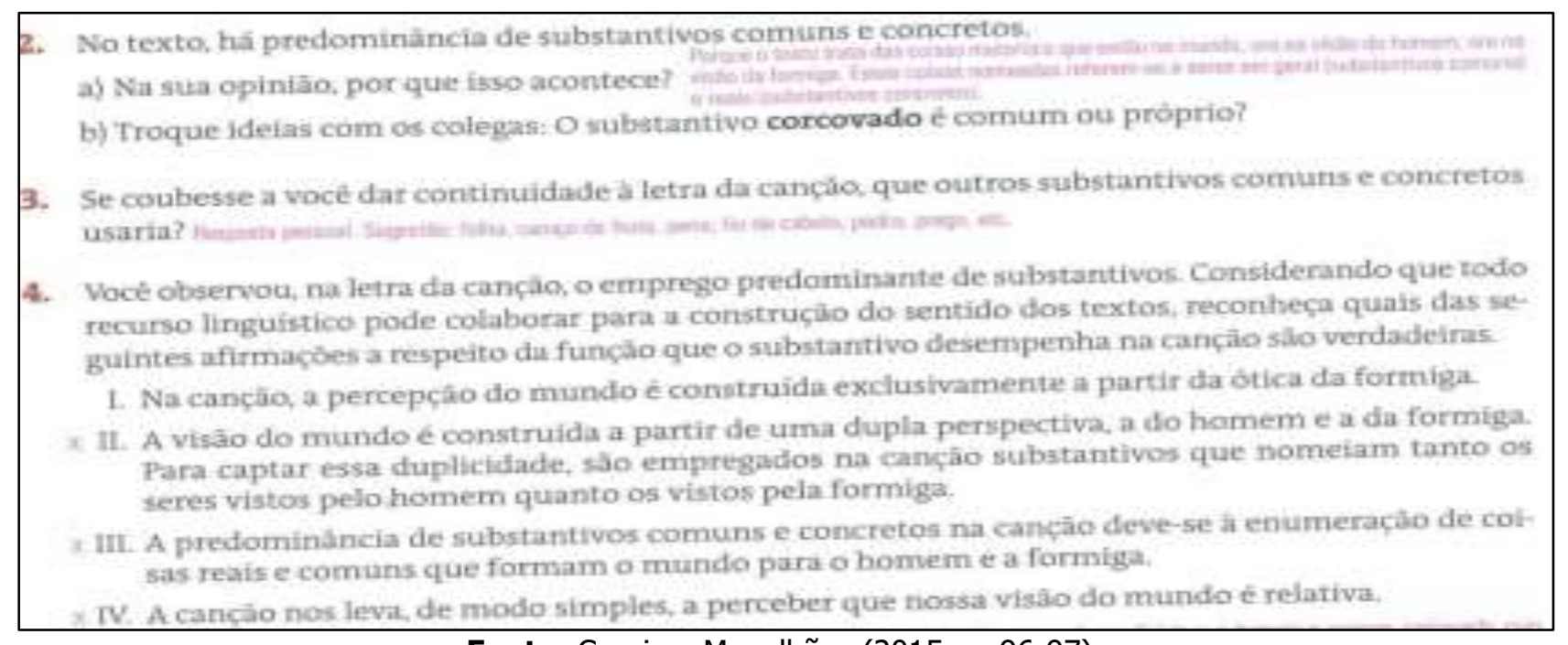

Fonte: Cereja e Magalhães (2015, p. 96-97)

Ao que identificamos no âmbito da canção "A formiga" e, em tom geral, no trato das demais canções analisadas, constatamos que, apesar de explorar a canção em alguns aspectos de sua textualidade e/ou de sua discursividade, as didatizações se ocupam em primeiro plano de tratar dos aspectos gramaticais da língua. Curiosamente, essa constatação revela certa controvérsia com o discurso que circula na seção que apresenta as concepções de linguagem empregadas na concepção do livro, notoriamente quando Cereja e Magalhães (2015, p. 304, grifo nosso) afirmam que:

[...] analisa-se o papel de determinada categoria gramatical na organização e na construção dos sentidos de um texto. Assim, o objetivo das atividades não é simplesmente o de constatar o emprego da categoria estudada, mas observar sua função semântica e estilística. Partindo do princípio de que as escolhas linguísticas do texto não são feitas ao acaso, mas orientadas pelo sentido pretendido pelo autor, esse trabalho visa demonstrar que essas escolhas (o suporte gramatical) são em grande parte responsáveis pela construção dos sentidos.

Os autores mencionam o uso das categorias gramaticais como caminho para se chegar aos sentidos do texto, mas podemos observar, por meio das didatizações nas três questões apresentadas, que a dimensão textual e a dimensão discursiva presente nas canções são exploradas de forma superficial. O contexto externo, constitutivo da linguagem na acepção dos gêneros discursivos, é vagamente discutido pelas questões em torno da canção na coleção analisada. O problema decorrente dessa pouca ênfase às condições concretas das situações de interação discursiva em que ocorrem os usos de linguagens, como já prenunciado, é exatamente a promoção de um ensino de língua pouco significativo e distante de uma preparação do educando para a concretude das práticas sociais às quais ele é circundado no cotidiano. 


\section{Considerações finais}

Pelas análises observadas nas três canções dispostas aqui, identificamos certo padrão quanto à metodologia de trabalho com as canções, haja vista que contemplam em alguns momentos, mas de maneira breve, aspectos ligados ao nível textual e/ou discursivo, para continuar fazendo referência e de maneira mais exaustiva ao funcionamento gramatical de determinados segmentos linguísticos. A situação concreta de produção é pouco ou sequer explorada, negligenciando um dos princípios da natureza da linguagem na visão bakhtiniana, de que "o signo e sua situação social estão fundidos de modo inseparável" (VOLÓCHINOV, 2017, p. 135).

A canção, nesse prisma, foi pouco explorada enquanto gênero textual. Nos movimentos de interpretação e compreensão textual identificados, percebemos superficialidade dos exercícios de leitura, ausência daqueles que dão margem à formação de questionamentos sobre os sentidos que estão postos no texto, algo que possibilitaria o desenvolvimento da criticidade e instigaria os discentes a se manifestarem mais ativamente na construção dos sentidos da canção.

Consideramos que quanto à perspectiva dos gêneros discursivos, nenhuma das canções recebeu essa abordagem. Tal proposta pressupõe, dentre outras coisas, que se dê oportunidades para que o aluno questione, reflita e reconheça traços inerentes à produção do enunciado. Uma consideração das canções como gêneros discursivos necessitaria estender a compreensão dos alunos ao contexto extralinguístico que, no horizonte da teoria dialógica, é constitutivo do dizer, traço que diferencia, dada a trajetória dos conceitos, as acepções de gênero discursivo e textual, por sua vez.

Com base nas atividades analisadas com a canção, recaímos no que sugere Rojo (2012), de que esses ainda se mantêm presos, de alguma maneira, a aspectos tradicionais, quanto à abordagem metodológica e pedagógica no ensino de língua portuguesa. Ainda que haja a busca por adequar-se aos documentos oficiais, como é o caso das teorias que contemplam o ensino e estudo por gêneros, se fazem muito fortes e presentes as concepções orientadas para a transmissão de conteúdos gramaticais. Logo, através desse gesto analítico, pudemos depreender que o trabalho com esse gênero segue na direção de pretexto para o ensino gramatical.

Por fim, como já é difundido ante os estudiosos do letramento e da produção de 
material didático, apontamos que, por um lado, nenhum material é plenivalente quanto ao alcance de toda e qualquer realidade educacional em que vem a ser empregado. Em outra vertente, destacamos que é necessário um desempenho crítico do trabalho docente, que permita didatizações do conhecimento cada vez mais coerentes com as reais necessidades humanas para os variados usos da linguagem.

\section{Referências}

BAKHTIN, Mikhail. Estética da criação verbal. Tradução Paulo Bezerra. 4. ed. São Paulo: Martins Fontes, 2003.

BAKHTIN, Mikhail. O discurso em Dostoiévski. In: BAKHTIN, Mikhail. Problemas da poética de Dostoiévski. Tradução Paulo Bezerra. Rio de Janeiro: Forense Universitária, 2015, p. 207-234.

BAKHTIN, Mikhail. Os gêneros do discurso. Tradução de Paulo Bezerra. São Paulo: Editora 34, 2016.

BARROS, Diana Luz Pessoa de. Contribuições de Bakhtin às teorias do discurso. In: BRAIT, Beth. (org.). Bakhtin, dialogismo e construção do sentido. 2. ed. Campinas: Ed. UNICAMP, 2005.

BRAIT, Beth. Perspectiva dialógica. In: BRAIT, Beth; SOUZA-E-SILVA, Maria Cecília (org.). Texto ou discurso? São Paulo: Contexto, 2012. p. 9-29.

BRAIT, Beth. Estilo. In: BRAIT, Beth. (org.). Bakhtin: conceitos-chave. 4. ed. São Paulo: Contexto, 2008. p.79-102.

BUNZEN JÚNIOR, Clecio dos Santos. Livro didático de língua portuguesa: um gênero do discurso. 2005. Dissertação (Mestrado em Linguística Aplicada) - UNICAMP, Campinas, 2005.

CALISSI, Luciana. A música popular brasileira nos livros didáticos de história. In: SIMPÓSIO NACIONAL DE HISTÓRIA, 23. Anais [...]. Londrina: ANPUH, 2005. p. 1-8.

CEREJA, William Roberto; MAGALHÃES Thereza Cochar. Português. linguagens ( $6^{\circ}$ ao $9^{\circ}$ ano). São Paulo: Saraiva, 2015. Manual do professor.

COSTA, Nelson Barros da. Canção popular e ensino de língua materna: o gênero canção nos Parâmetros Curriculares de Língua Portuguesa. Linguagem em (Dis)curso, Tubarão, v. 4, n. 1, p. 9-36, jul./dez., 2003. Disponível em:

http://www.portaldeperiodicos.unisul.br/index.php/Linguagem_Discurso/article/view/253. Acesso em: 11 mar. 2021. 
FARACO, Carlos Alberto. Linguagem \& diálogo: as ideias linguísticas do círculo de Bakhtin. São Paulo: Parábola Editorial, 2009.

FERREIRA, Martins. Como usar a música em sala de aula. São Paulo: Contexto, 2002.

FIORIN, José Luiz de. Introdução ao pensamento de Bakhtin. 2. ed. São Paulo: Contexto, 2017.

FOUCAULT, Michel. Estética: literatura e pintura, música e cinema. 2. ed. Rio de Janeiro: Forense Universitária, 2006. v. 3.

GADA, ANA LÚCIA COLODETTI. A canção no livro didático de língua portuguesa. 2005. Dissertação (Mestrado em Estudos Linguísticos) - Universidade Estadual de Maringá, Maringá, 2005.

MARCUSCHI, Luiz Antônio. Gêneros textuais: definição e funcionalidade. In: DIONÍSIO, Angela Paiva; MACHADO, Anna Rachel; BEZERRA, Maria Auxiliadora (org.). Gêneros textuais e ensino. 5. ed. Rio de Janeiro: Lucerna, 2007. p. 1-16.

MUNAKATA, Kazumi. Livro didático e formação do professor são incompatíveis? In: Ângela Paiva Dionísio Kazumi Munakata Márcia de Paula Gregório Razzini (org.). O livro didático e a formação de professores. Brasília: MEC, 2002. p. 89-94.

ROJO, Roxane. Pedagogia dos multiletramentos: diversidade cultural e de linguagens na escola. In: ROJO, Roxane; MOURA, Eduardo (org.). Multiletramentos na escola. São Paulo: Parábola Editorial, 2012. p. 11-31.

ROJO, Roxane; BARBOSA, Jacqueline Peixoto; MARCIONILO, Marcos. Hipermodernidade, multiletramentos e gêneros discursivos. São Paulo: Parábola Editorial, 2015.

SILVA, Adriana Pucci Penteado de Faria e. Texto e enunciado concreto: chegadas e partidas. Eutomia: Revista de Literatura e Linguística, Recife, v. 1, n.9, p. 207-223, 2012. Disponível em: https://periodicos.ufpe.br/revistas/EUTOMIA/article/view/945. Acesso em: 11 mar. 2021.

SOBRAL, Adail. Do dialogismo ao gênero: as bases do pensamento do círculo de Bakhtin. Campinas: Mercado das Letras, 2009.

STREET, Brian V. Letramentos sociais: abordagens críticas do letramento no desenvolvimento, na etnografia e na educação. Tradução de Marcos Bagno. São Paulo: Parábola Editorial, 2014.

VIANA, Layane Dias Cavalcante. Abordagem discursiva do livro didático de Língua Portuguesa: um gênero do discurso complexo. 2011. Dissertação (Mestrado em Cultura, Educação e Linguagens) - Universidade Estadual do Sudoeste da Bahia, Vitória da Conquista, 2011. 
VOLÓCHINOV, Valentin. Marxismo e filosofia da linguagem: problemas fundamentais do método sociológico na ciência da linguagem. Tradução Sheila Grillo e Ekaterina Vólkova Américo. São Paulo: Editora 34, 2017.

Submetido em: 11 mar. 2021. Aceito em: 01 jun. 2021. 